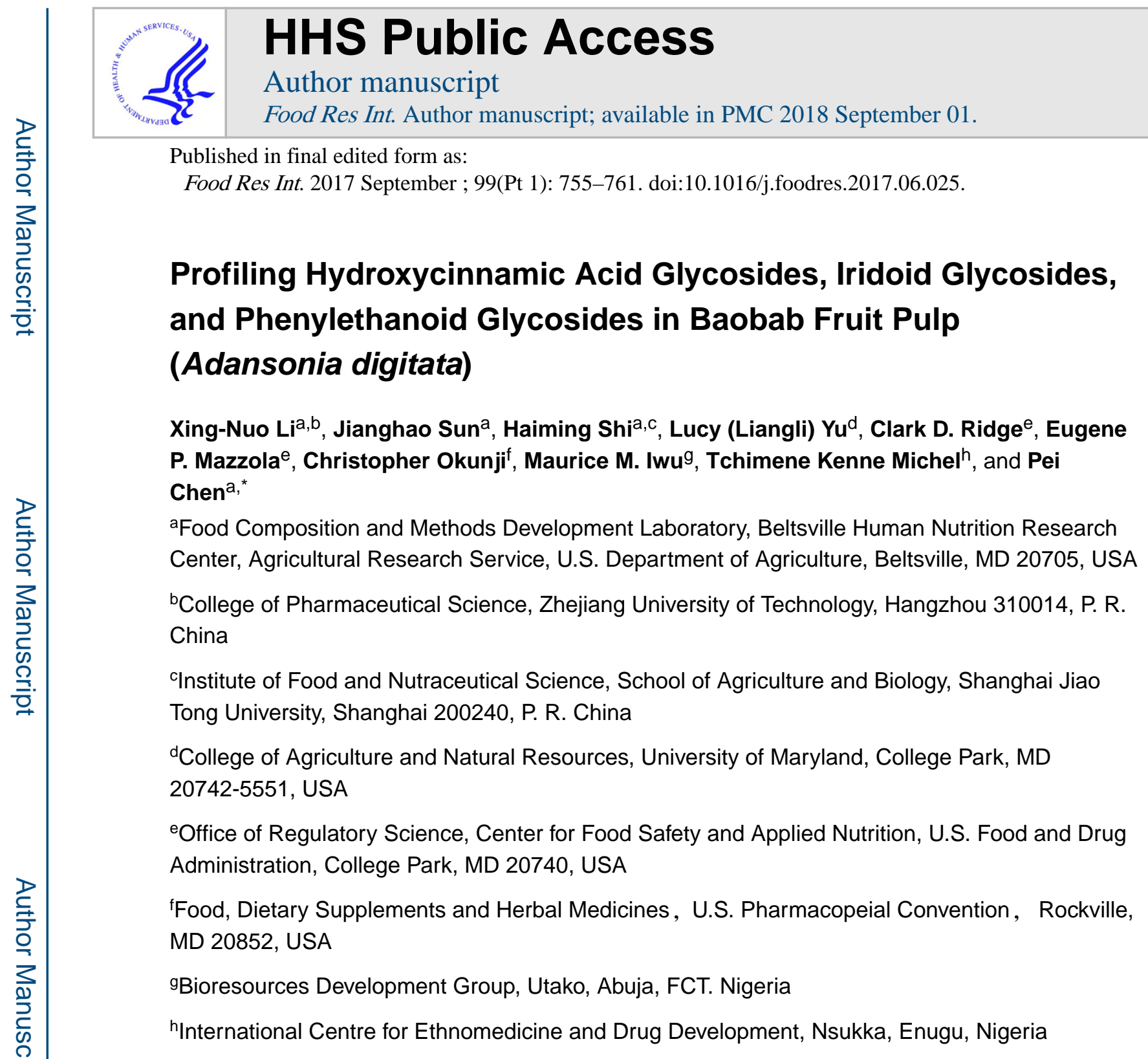

\begin{abstract}
The baobab (Adansonia digitata L.) is a magnificent tree revered throughout Africa and is becoming recognized for its high nutritional and medicinal values. Despite numerous reports on the pharmacological potential, little is known about its chemical compositions. In this study, four hydroxycinnamic acid glycosides (1-4), six iridoid glycosides (5-10), and three phenylethanoid
\end{abstract}

\footnotetext{
*Corresponding author: Tel: 301-504-8144; Fax: 301-504-8314, pei.chen@ars.usda.gov.

Publisher's Disclaimer: This is a PDF file of an unedited manuscript that has been accepted for publication. As a service to our customers we are providing this early version of the manuscript. The manuscript will undergo copyediting, typesetting, and review of the resulting proof before it is published in its final citable form. Please note that during the production process errors may be discovered which could affect the content, and all legal disclaimers that apply to the journal pertain.

Supplementary data

The conditions of UHPLC-DAD-HRMS ${ }^{\mathrm{n}}$.

The process of isolation.

${ }^{1} \mathrm{H}(600 \mathrm{MHz})$ and ${ }^{13} \mathrm{C}(150 \mathrm{MHz}) \mathrm{NMR}$ (methanol- $\left.d_{4}\right)$ data of compounds $\mathbf{1}-\mathbf{1 3}$.

The MS ${ }^{\mathrm{n}}$ spectra of Compounds $2, \mathbf{3}, \mathbf{5}, \mathbf{8}$ and $\mathbf{1 2}$.

The hydroxycinnamic acid glycosides (HAGs), iridoid glycosides (IGs), and phenylethanoid glycosides (PGs) identified by HRMS ${ }^{\mathrm{n}}$ in baobab.
} 
glycosides (11-13) were isolated from the dried baobab fruit pulp. Their structures were determined by means of spectroscopic analyses, including HRMS, ${ }^{1} \mathrm{H}$ and ${ }^{13} \mathrm{C}$ NMR and 2D experiments (COSY, HSQC, HMBC, and ROESY). All 13 compounds isolated were reported for the first time in the genus of Adansonia. An ultra high-performance liquid chromatography highresolution accurate-mass mass spectrometry (UHPLC HRAM MS) method was used to conduct further investigation of the chemical compositions of the hydro-alcohol baobab fruit pulp extract. Hydroxycinnamic acid glycosides, iridoid glycosides and phenylethanoid glycosides were found to be the main components in baobab fruit pulp.

\section{Graphical abstract}

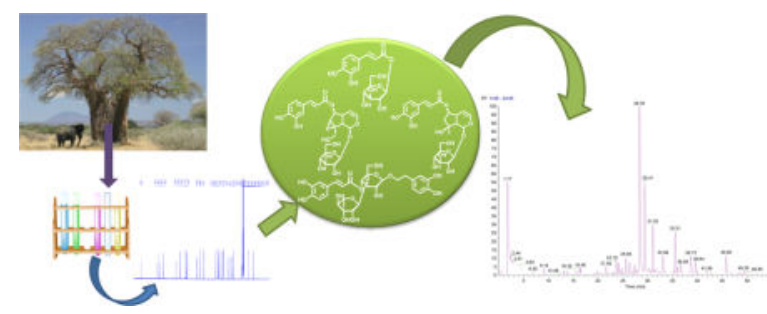

\section{Keywords}

baobab; Adansonia digitata; chemical constituents; NMR; UHPLC-HRMS ${ }^{\text {n }}$

\section{Introduction}

The genus Adansonia L. (Malvaceae) is well known as baobab, upside-down tree, Monkeybread tree, amongst several other names. This genus comprises nine species and most of them occur naturally in Africa (Kamatou, Vermaak, \& Viljoen, 2011). Adansonia digitata commonly known as 'Baobab' is found primarily in the Sahelian, Soudano-Sahelian, and Soudanian zones. It is a massive deciduous tree easily distinguishable by its huge trunk and can grow up to 25-meter or more in height, 12-meter in diameter and may live for several hundred years (Chadare, Linnemann, Hounhouigan, Nout, \& Van Boekel, 2009). Some baobabs bear leaves only for three months per year. And most of the biosynthetic processes of secondary metabolites take place in the trunk and branches during the long leafless period (Gebauer, El-Siddig, \& Ebert, 2002).

The baobab is considered bewitched by some indigenous people throughout Africa. It has multi-purpose uses and every part of the plant is reported to be useful. The products of baobab such as bark, leaves, fruits and seeds contribute to the livelihood of many populations in Africa as a source of food or medicine (Chadare, Linnemann, Hounhouigan, Nout, \& Van Boekel, 2009; De Caluwe, Halamova, \& Van Damme, 2010). The leaves, bark and fruit pulp have been traditionally used as immunostimulants, analgesics etc. in the treatment of diseases such as fever, diarrhea, cough, dysentery, haemoptysis, tuberculosis, microbial infection and worms (De Caluwe, Halamova, \& Van Damme, 2010; Denloye, Teslim, \& Fasasi, 2006; Kamatou, Vermaak, \& Viljoen, 2011; Rahul et al., 2015; Yusha'u, Hamaza, \& Abdullahi, 2010). The seeds and oil are used as medicines in the treatment of muscle wounds, dandruff and other skin ailments (Kamatou, Vermaak, \& Viljoen, 2011; 
Kabore et al., 2011). Thus the tree is nick named as 'The small pharmacy tree' or 'Chemist tree'. Baobab fruit pulp is low in protein and fat, but rich in pectins, calcium, minerals, vitamin $\mathrm{B}$, and it contains seven to ten times higher content of vitamin $\mathrm{C}$ than oranges. It can be dissolved in water or milk and used as a drink and sauce for food or as a substitute for cream in baking. Recently, baobab has been referred to as a 'super fruit' because of its nutritional profile (Rahul et al. 2015).

Baobab fruit pulp has been approved by statutory bodies for use in certain nutritional products. In 2008 the European Commission authorized the dried fruit pulp of baobab as a novel food (Buchmann, Prehsler, Hartl, \& Vogl, 2010). Baobab fruit pulp was also approved as a food ingredient in the United States of America in 2009 (FDA, 2009). The products derived from fruit pulp have been exported to European and USA markets and the demand for these products are increasing. In order to meet the demands of the new commercial markets, studies were undertaken to determine factors that are important to the cultivation of baobab. In some areas of Burkina Faso and India, the planting of baobab trees has been started (Kamatou, Vermaak, \& Viljoen, 2011; Sanchez, Osborne, \& Haq, 2010).

It is evident that the iconic African tree, baobab, is an important nutritional and medicinal resource. In the past decade, it has attracted the interest of a lot of scientists and pharmaceutical companies. And numerous studies have been conducted on the biological activities of baobab. This paper will present a systematic structural characterization of the constituents in baobab fruit pulp. Data for hydroxycinnamic acid glycosides (HAGs), iridoid glycosides (IGs), and phenylethanoid glycosides (PGs) are presented. This information is of great significance for its nutritional and medicinal applications.

\section{Materials and methods}

\subsection{Chemicals and materials}

HPLC grade methanol, acetonitrile and formic acid were purchased from VWR International, Inc. (Clarksburg, MD). HPLC water was purchased from Sigma-Aldrich (St. Louis, MO).

The fruits of $A$. digitata were collected from Abagana, Anambra State, Nigeria in July 2013, and identified by Mr. Ozioko A. A voucher specimen (No INTERCEDD0613) has been deposited in Food Composition and Methods Development Laboratory, Beltsville Human Nutrition Research Center, Agricultural Research Service.

\subsection{Extraction process for isolation and analysis}

The air-dried fruits of $A$. digitata $(0.8 \mathrm{~kg})$ were powdered and extracted with $70 \%(\mathrm{~V} / \mathrm{V})$ $\mathrm{EtOH}-\mathrm{H}_{2} \mathrm{O}$ for three times (one hour for each time) to give $75 \mathrm{~g}$ of crude extract, which was dissolved in $750 \mathrm{~mL}$ of $\mathrm{H}_{2} \mathrm{O}$ to form a suspension and successively partitioned with ethyl acetate $(750 \mathrm{~mL} \times 3)$ and $n$-butanol $(750 \mathrm{~mL} \times 3)$.

The fruits were ground into powder and passed through a 60 mesh sieve. Five hundred milligram fruit powders were extracted with $5.00 \mathrm{~mL}$ of methanol-water $(60: 40, \mathrm{v} / \mathrm{v})$ with sonication for $30 \mathrm{~min}$ at ambient temperature. The slurry mixture was centrifuged at 5,000 g 
for 15 minutes. The supernatant was filtered through a $17 \mathrm{~mm}(0.20 \mu \mathrm{m})$ PVDF syringe filter (VWR Scientific, Seattle, WA, USA) and stored at $4^{\circ} \mathrm{C}$ before analysis. All analyses were done within 24 hours of extraction. The injection volume for all samples was $1 \mu \mathrm{L}$.

\title{
2.3. NMR
}

\begin{abstract}
${ }^{1} \mathrm{H}$ and ${ }^{13} \mathrm{C}$ NMR were recorded on a Bruker AVIII-600MHz spectrometer (Bruker, Rheinstetten, Germany) and a Varian VNMRS-600MHz spectrometer (Agilent Technologies, Santa Clara, CA) operating at $600 \mathrm{MHz}$ for ${ }^{1} \mathrm{H}$ NMR and $150 \mathrm{MHz}$ for ${ }^{13} \mathrm{C}$ NMR at ambient temperature in methanol- $d_{4}$. The chemical shifts $(\delta)$ are reported in ppm referenced to the residual solvent peak. The coupling constants $(J)$ are quoted in hertz.
\end{abstract}

The conditions of UHPLC-DAD-HRMS ${ }^{\mathrm{n}}$ are presented in the Supporting Information.

The process of isolation is presented in the Supporting Information.

${ }^{1} \mathrm{H}$ and ${ }^{13} \mathrm{C}$ Data for hydroxycinnamic acid glycosides (HAGs), iridoid glycosides (IGs), and phenylethanoid glycosides (PGs) are presented in the Supporting Information.

\section{Results and discussion}

\subsection{Chemical Constituents Obtained from Baobab}

The current study isolated four hydroxycinnamic acid glycosides (HAGs): 1- $O$-(E)-feruloyl$\beta$-D-glucose (1) (Jaiswal \& Kuhnert, 2014; Jaiswal, Matei, Glembockyte, Patras, \& Kuhnert, 2014), 1- $O$-(E)-caffeoyl- $\beta$-D-glucose (2) (Jaiswal \& Jaiswal \& Kuhnert, 2014; Jaiswal, Matei, Glembockyte, Patras, \& Kuhnert, 2014), 6- $O$-(E)-caffeoyl- $\beta$-D-glucose (3) (Jaiswal \& Kuhnert, 2014; Jaiswal, Matei, Glembockyte, Patras, \& Kuhnert, 2014), 6- $O-(E)$-caffeoyl$a$-D-glucose (4) (Jaiswal \& Kuhnert, 2014; Jaiswal, Matei, Glembockyte, Patras, \& Kuhnert, 2014), six iridoid glycosides (IGs): (-)-specioside (5) (Sha'aban, El-Naggar, \& Doskotch, 1980), verminoside (6) (Sticher \& Afifi-Yazar, 1979), 6- $O$-(E)-feruloylcatalpol (7) (Young, Kim, Park, Chung, \& Choi, 1992), 6-O-p-coumaroylajugol (8) (Nishimura, Sasaki, Morota, Chin, \& Mitsuhashi, 1989), 6- $O-(E)$-caffeoylajugol (9) (Harinantenaina Liva, Kasai, Rakotocao, \& Yamasaki, 2001), 6- $O$-(E)-feruloylajugol (10) (Li et al., 2011), and three phenylethanoid glycosides (PGs): martynoside (11) (Li et al., 2011; Sasaki, Nishimura, Chin, \& Mitsuhashi, 1989), acteoside (12) (Li et al., 2011; Sasaki, Nishimura, Chin, \& Mitsuhashi, 1989), isoacteoside (13) (Kim, Kim, Jung, Ham, \& Whang, 2009) from the baobab fruit pulp (Figure 1 and Table 1). Their structures were established on the basis of spectroscopic data, particularly the 1D NMR and several 2D shift-correlated NMR pulse sequences $\left({ }^{1} \mathrm{H}^{-}{ }^{1} \mathrm{H} \mathrm{COSY}, \mathrm{HSQC}, \mathrm{HMBC}\right.$ and ROESY). All of the compounds were obtained from genus of Adansonia for the first time.

\subsection{Putative Identification of HAGs, IGs, and PGs Using UHPLC-DAD-HRMS ${ }^{n}$}

HAGs, IGs, and PGs were studied using an UHPLC-DAD-HRMS ${ }^{\mathrm{n}}$ method (Figure $2 \& 3$ ).

3.2.1. Identification of HAGs-Most HAGs in baobab fruit pulp are formed from hydroxycinnamic acid ( $p$-coumaroyl, caffeoyl, feruloyl, etc.) and mono-, di-, and 
trisaccharides. These compounds are found as the primary phenolic compounds in many common plant derived foods (Lin, Harnly, Zhang, Fan, \& Chen, 2012).

Compound $\mathbf{1}-\mathbf{4}$ are the HAGs in baobab fruit pulp (Figure 2). They were isolated and their identifications were confirmed by NMR spectroscopic data.

As shown in Table 1, compounds $\mathbf{2}, \mathbf{3}$, and $\mathbf{4}$ displayed $[\mathrm{M}-\mathrm{H}]^{-}$ion at $\mathrm{m} / \mathrm{z} 341$ with the same elemental composition of $\mathrm{C}_{15} \mathrm{H}_{18} \mathrm{O}_{9}$. They showed the similar fragment ions at $\mathrm{m} / \mathrm{z}$ 281, 251, 221, 179 and 161 in MS/MS. The diagnostic ions at $\mathrm{m} / z 179$ and 161 suggested the presence of the caffeoyl moiety. The loss of 162 mass unit indicated the existence of a hexose. Based on the $\mathrm{MS}^{2}$ spectra and the information obtained from the literatures (Jaiswal \& Kuhnert, 2014; Jaiswal, Matei, Glembockyte, Patras, \& Kuhnert, 2014), the fragment ions at $\mathrm{m} / \mathrm{z} 281,251$ and 221 were obtained through the ring fission fragmentation of the hexose (Scheme 1). Compounds 3 and $\mathbf{4}$, which are the $\alpha / \beta$ anomers of 6-caffeoylglucose, can be distinguished from $\mathbf{2}$ based on the base peak of $\mathbf{3}$ and $\mathbf{4}$ at $\mathrm{m} / z 281$ and that of $\mathbf{2}$ at $\mathrm{m} / z 179$. The intensities of specific fragment ions were the key evidence for the identification of the linkage position between the hydroxycinnamic acid and the saccharide in HAGs. In MS/MS of 1- $O-(E)$-feruloyl- $\beta$-D-glucose (1), fragment ions at $\mathrm{m} / z$ 295, 265, 235, 193 and 175 were the characteristic ions for the feruloyl group and the hexose. And the base peak at $\mathrm{m} / z 193$ provided the evidence for the identification of 1- $O$-feruloyl-hexose.

3.2.2. Identification of IGs-Based on our phytochemical investigation, IGs were the predominant constituents in baobab and most of them were the derivatives of catalpol and ajugol, in which the cyclopentanoid unit of the characteristic 9-C framework was fused with a dihydropyran ring by a cis-junction. A glucose moiety was usually linked to $\mathrm{C}-1$ position.

Compound 5-10 are IGs in baobab fruit pulp (Figure 2). They were isolated and their identifications were confirmed by NMR spectroscopic data.

3.2.2.1. Group I: Group I were the derivatives of ajugol such as compounds $\mathbf{5}, \mathbf{6}$ and $\mathbf{7}$. They were the epoxytane-type iridoid glycosides: an aglycone oxygen bridge was adjacent to $\mathrm{C}-7$ and $\mathrm{C}-8$ positions of the skeleton. A hexose residue was linked to $\mathrm{C}-1$ position. And the skeleton was substituted by hydroxyl derivatives of the cinnamic acid (coumaroyl, caffeoyl, feruloyl, etc.).

Based on the retention time and the MS data, (-)-specioside (5), verminoside (6), 6- $O-(E)$ feruloylcatalpol (7) were respectively identified. And verminoside (6) was one of the main constituents in the baobab fruit pulp extracts.

Compound 5 displayed $[\mathrm{M}-\mathrm{H}]^{-}$ion at $\mathrm{m} / z 507.1498$ with the molecular formula of $\mathrm{C}_{24} \mathrm{H}_{28} \mathrm{O}_{12}$. As shown in Table 1 and Scheme 2a, fragmentation of this precursor ion yielded several characteristic product ions. The fragment ion at $\mathrm{m} / z 345.0974$ in MS/MS was obtained through the cleavage of the glycosidic bond, with the neutral loss of a glucose moiety $\left(-162.0524 \mathrm{amu}, \mathrm{C}_{6} \mathrm{H}_{10} \mathrm{O}_{5}\right)$. The product ion at $\mathrm{m} / \mathrm{z} 231.0658$ was formed by the ring-open reaction on the basis of the isomerization of the hemiacetal group. The fragment 
ions at $\mathrm{m} / \mathrm{z} 163.0398$ and 145.0293 indicated the existence of the coumaroyl group (Scheme 2a).

Compound 6 displayed $[\mathrm{M}-\mathrm{H}]^{-}$ion at $\mathrm{m} / z 523.1434$ with the molecular formula of $\mathrm{C}_{24} \mathrm{H}_{28} \mathrm{O}_{13}$. Fragmentation of deprotonated ion at $\mathrm{m} / z 523$ yielded a series of characteristic fragment ions at $\mathrm{m} / \mathrm{z} 361.0922,247.0603,179.0347$ and 161.0241. And in $\mathrm{MS}^{2-4}$ spectra of 7, a series of characteristic fragment ions at $\mathrm{m} / \mathrm{z} 375.1081,261.0764,193.0506$ and 175.0401 were obtained through the fragmentation of $[\mathrm{M}-\mathrm{H}]^{-}$ion at $\mathrm{m} / z$ 537.1598. They were respectively 16 and 30 mass units greater than the corresponding fragment ions of $\mathbf{5}$. These results suggest that compounds 5, $\mathbf{6}$ and $\mathbf{7}$ had the same iridoid aglycone skeleton which differed in the substitutions at C-6 position. And the substitutions of 6 and 7 at C-6 position were caffeoyl (179/161) and feruloyl (193/175) moieties, respectively. Based on this analysis, the proposed fragmentation patterns for compounds 5,6 and 7 provided abundant structural skeleton information and were related to the structural characteristics.

3.2.2.2. Group II: Group II were the derivatives of catalpol such as compounds 8,9 and $\mathbf{1 0}$. They were characterized as cyclopentane-type iridoid glycosides with no double bond within the five-membered-ring. A hexose residue was linked to $\mathrm{C}-1$ position. The skeleton was substituted by hydroxyl derivatives of the cinnamic acid (coumaroyl, caffeoyl, feruloyl, etc.).

Compound 8 exhibited a $[\mathrm{M}-\mathrm{H}]^{-}$ion at $\mathrm{m} / z 493.1707$ with the molecular formula of $\mathrm{C}_{24} \mathrm{H}_{30} \mathrm{O}_{11}$. The MS/MS spectrum of $[\mathrm{M}-\mathrm{H}]^{-}$revealed a fragment ion at $\mathrm{m} / z$ 331.1182, produced by the cleavage of a glucose moiety. The fragment ions at $\mathrm{m} / z 163.0399$ and 145.0293 indicated the existence of the coumaroyl group. (Scheme 2b)

Compound 9 displayed the $[\mathrm{M}-\mathrm{H}]^{-}$ion at $\mathrm{m} / z 509.1644$ with the molecular formula of $\mathrm{C}_{24} \mathrm{H}_{30} \mathrm{O}_{12}$. Fragmentation of deprotonated ion at $\mathrm{m} / z$ 509.1644 yielded a series of characteristic fragment ion at $\mathrm{m} / z$ 347.1130, 179.0348 and 161.0242. And in $\mathrm{MS}^{\mathrm{n}}$ spectra of compound 10, a series of characteristic fragment ions at $\mathrm{m} / z 361.1285,193.0505$ and 175.0399 were obtained through the fragmentation of $[\mathrm{M}-\mathrm{H}]^{-}$ion at $\mathrm{m} / z 523.1800$. They were respectively 16 and 30 mass unit higher than the corresponding fragment ions of $\mathbf{8}$. These results suggest that compounds $\mathbf{8 , 9}$ and $\mathbf{1 0}$ had the same iridoid aglycone skeleton that differed in the substitutions at C-6 position. And the substitutions of $\mathbf{9}$ and $\mathbf{1 0}$ at C-6 position were caffeoyl (179/161) and feruloyl (193/175) moieties, respectively.

3.2.3. Identification of PGs-Phenylethanoid glycosides are characterized by a $\beta$ glycopyranose directly attached to the hydroxyphenylethyl moiety. The hydroxyl derivatives of the cinnamic acid (coumaroyl, caffeoyl, feruloyl, etc.) are usually attached to the C-4 or $\mathrm{C}-6$ positions of $\beta$-glycopyranose. A rhamnose is usually located at the $\mathrm{C}-3$ position of $\beta$ glycopyranose. For phenylethanoid glycosides with a trisaccharide moiety, an additional glucose is usually substituted at the C-6 position of $\beta$-glycopyranose. The typical losses in $\mathrm{MS}^{2}$ include the loss of the feruloyl moiety (176 amu), the caffeoyl or the hexose moiety (162 amu), and the coumaroyl or the deoxyhexose moiety (146 amu). The loss of 18, 32, and 42 mass unit indicated the existence of the hydroxyl, the methoxyl, and the acetyl in the structure of phenylethanoid glycosides (Cao et al., 2011; Li, Liu, Abdulla, Aisa, \& Suo, 2014a; Li, Liu, Abdulla, Aisa, \& Suo, 2014b). For these types of compounds, the MS ${ }^{\mathrm{n}}$ data 
cannot give adequate information about the substituent positions of the ester groups without reference compounds or related literatures on this plant.

Compound $\mathbf{1 1} \mathbf{- 1 3}$ are IGs in baobab fruits (Figure 2). They were isolated and their identifications were confirmed by NMR spectroscopic data.

As shown in Table 1, compound $\mathbf{1 2}$ and $\mathbf{1 3}$ displayed $[\mathrm{M}-\mathrm{H}]^{-}$ion at $\mathrm{m} / z 623$ with the same elemental composition of $\mathrm{C}_{29} \mathrm{H}_{36} \mathrm{O}_{15}$. They showed similar fragment ions at $\mathrm{m} / z 461,315$, and 135 in $\mathrm{MS}^{\mathrm{n}}$. The fragment ion at $\mathrm{m} / z 461$ in $\mathrm{MS}^{2}$ was produced by the neutral loss of a caffeoyl moiety. The neutral loss of a deoxyhexose from the precursor ion at $m / z 461$ in $\mathrm{MS}^{3}$ gave a fragment ion at $\mathrm{m} / z 315$. In $\mathrm{MS}^{4}$, the fragment ion at $\mathrm{m} / z 135$ demonstrated the loss of a hexose (180 amu) from the ion at $\mathrm{m} / z 461$ and the existence of a 3,4-dihydroxy phenethyl residue. (Scheme 3)

Martynoside (11) gave a deprotonated ion at $\mathrm{m} / \mathrm{z} 651.2281$. The ion observed at $\mathrm{m} / \mathrm{Z}$ 475.1817 in $\mathrm{MS}^{2}$ was obtained through the loss of a feruloyl residue and the loss of a deoxyhexose gave the ion at $\mathrm{m} / \mathrm{z} 329.1329$ in $\mathrm{MS}^{3}$.

\section{Conclusion}

Hydroxycinnamic acid glycosides which are considered to be anti-inflammatory, anticarcinogenic, and antimicrobial agents were frequently reported as constituents in human diet (Jaiswal \& Kuhnert, 2014; Jaiswal, Matei, Glembockyte, Patras, \& Kuhnert, 2014; Kylli, Nousiainen, Biely, Sipila, Tenkanen, \& Heinonen, 2011). Naturally occurring iridoid glycosides and phenylethanoid glycosides which are widely distributed in plants have stimulated the research interest due to their wide range of health-promoting bioactivity such as antioxidant, anti-inflammatory, antimicrobial and antiviral effect (Dinda, Debnath, \& Banik, 2011; Tundis, Loizzo, Menichini, Statti, \& Menichini, 2008; Xue, \& Yang, 2016; Fu, Pang, \& Wong, 2008).

In the present study, the systematic phytochemical research led to the isolation and putative identification of four HAGs (1-4), six IGs (5-10), and three PGs (10-13). What is noteworthy is that all 13 compounds were isolated from the genus of Adansonia for the first time. Among them, (-)-specioside (5), verminoside (6), 6- $O$-(E)-caffeoylajugol (9), martynoside (11), acteoside (12), and isoacteoside (13) have been obtained from Kigelia africana which is another native medical plant of the African continent (Bello, Shehu, Musa, \& Asmawi, 2016). IGs and PGs have chemotaxonomic importance and can be used to establish taxonomic relations between two genera. Moreover, the presence of the organic acid moieties, such as the cinnamoyl, the caffeoyl, and the feruloyl, is the most obvious characteristic and may contribute to the pharmacologic actions of those compositions.

\section{Supplementary Material}

Refer to Web version on PubMed Central for supplementary material. 


\section{Acknowledgments}

This research is supported by the Agricultural Research Service of the U.S. Department of Agriculture and an Interagency Agreement with the Office of Dietary Supplements of the National Institutes of Health. It was also financially supported by the National Natural Science Foundation of China (NO. 81502941) and Zhejiang Provincial Natural Science Foundation of China (NO. LY16H300006).

\section{Appendix A. Supplementary data}

Supplementary dataassociated with this article can be found, in the online version, at http://

\section{References}

Bello I, Shehu MW, Musa M, Asmawi MZ. Kigelia africana (Lam.) Benth. (Sausage tree): Phytochemistry and pharmacological review of a quintessential African traditional medicinal plant. Journal of Ethnopharmacology. 2016; 189:253-276. [PubMed: 27220655]

Buchmann C, Prehsler S, Hartl A, Vogl CR. The importance of baobab (Adansonia digitata L.) in rural west african subsistence-suggestion of a cautionary approach to international market export of baobab fruits. Ecology of Food and Nutrition. 2010; 49:145-172. [PubMed: 21883078]

Cao X, Qiao J, Wang L, Ye X, Zheng L, Jiang N, Mo W. Screening of glycoside isomers in $P$. scrophulariiflora using ionic liquid-based ultrasonic-assisted extraction and ultra-performance liquid chromatography/electrospray ionization quadrupole time-of-flight tandem mass spectrometry. Rapid Communications in Mass Spectrometry. 2011; 26:740-748.

Chadare FJ, Linnemann AR, Hounhouigan JD, Nout MJR, Van Boekel MAJS. Baobab food products: a review on their composition and nutritional value. Critical Reviews in Food Science and Nutrition. 2009; 49:254-274. [PubMed: 19093269]

De Caluwe E, Halamova K, Van Damme P. Adansonia digitata L. - a review of traditional uses, phytochemistry and pharmacology. Afrika Focus. 2010; 23:11-51.

Denloye AAB, Teslim KO, Fasasi OA. Insecticidal and repellency effects of smoke from plant pellets with or without D-allethrin 90 EC against three medical insects. Journal of Entomology. 2006; 3:915.

Dinda B, Debnath S, Banik R. Naturally occurring iridoids and secoiridoids. An updated review, Part 4. Chemical \& Pharmaceutical Bulletin. 2011; 59:803-833. [PubMed: 21720031]

FDA (U.S. Food and Drug Administration). Agency Response Letter GRAS Notice No GRN 000273. 2009. URL (http://www.fda.gov/food/ingredientspackaginglabeling/gras/noticeinventory/ ucm174945.htm)

Fu G, Pang H, Wong YH. Naturally occurring phenylethanoid glycosides: Potential leads for new therapeutics. Current Medical Chemistry. 2008; 15:2592-2613.

Gebauer J, El-Siddig K, Ebert G. Baobab (Adansonia digitata L.): a review on a multipurpose tree with promising future in Sudan. Gartenbauwissenschaft. 2002; 67:155-160.

Harinantenaina Liva RR, Kasai R, Rakotovao M, Yamasaki K. New iridoid and phenethyl glycosides from Malagasy medicinal plant, Phyllarthron madagascariense. Nature Medicine. 2001; 55:187192.

Jaiswal R, Kuhnert N. Identification and characterization of the phenolic glycosides of Lagenaria siceraria Stand. (Bottle Gourd) fruit by liquid chromatography-tandem mass spectrometry. Journal of Agricultural and Food Chemistry. 2014; 62:1261-1271. [PubMed: 24447091]

Jaiswal R, Matei MF, Glembockyte V, Patras MA, Kuhnert N. Hierarchical key for the LC-MS ${ }^{\text {n }}$ identification of all ten regio- and steroisomers of caffeoylglycose. Journal of Agricultural and Food Chemistry. 2014; 62:9252-9265. [PubMed: 25184485]

Kabore D, Sawadogo-Lingani H, Diawara B, Compaore CS, Dicko MH, Jakobsen M. A review of baobab (Adansonia digitata) products: effect of processing techniques, medicinal properties ans uses. African Journal of Food Science. 2011; 5:833-844.

Kamatou GPP, Vermaak I, Viljoen AM. An updated review of Adansonia digitata: A commercially important African tree. South African Journal of Botany. 2011; 77:908-919. 
Kim KH, Kim S, Jung MY, Ham IH, Whang WK. Anti-inflammatory phenylpropanoid glycosides from Clerodendron trichotomum leaves. Archives of Pharmacal Research. 2009; 32:7-13. [PubMed: 19183871]

Kylli P, Nousiainen P, Biely P, Sipila J, Tenkanen M, Heinonen M. Antioxidant potential of hydroxycinnamic acid glycoside esters. Journal of Agricultural and Food Chemistry. 2008; 56:4797-4805. [PubMed: 18494493]

Li C, Liu Y, Abdulla R, Aisa HA, Suo Y. Characterization and identification of chemical components in Neopicrorhiza scrphulariiflora roots by liquid chromatography-electrospray ionization quadrupole time-of-flight tandem mass spectrometry. Analytical Methods. 2014a; 6:3634-3643.

Li C, Liu Y, Abdulla R, Aisa HA, Suo Y. Determination of phenylethanoid glycosides in Lagotis brevituba Maxim. by high-performance liquid chromatography-electrospray ionization tandem mass spectrometry. Analytical Letters. 2014b; 47:1862-1873.

Li XN, Zhou MY, Shen PQ, Zhang JB, Chu C, Ge ZW, Yan JZ. Chemical constituents of Rehmannia glutinosa. Chinese Journal of Chinese Materia Medica. 2011; 36:3125-3129.

Lin LZ, Harnly J, Zhang RW, Fan XE, Chen HJ. Quantitation of the hydroxycinnamic acid derivatives and the glycosides of flavonols and flavones bu UV absorbance after identification by LC-MS. Journal of Agricultural and Food Chemistry. 2012; 60:544-553. [PubMed: 22136064]

Nishimura H, Sasaki H, Morota T, Chin M, Mitsuhashi H. Six iridoid glycosides from Rehmannia glutinosa. Phytochemistry. 1989; 28:2705-2709.

Rahul J, Jain MK, Singh SP, Kamal RK, Anuradha, Naz A, Gupta AK, Mrityunjay SK. Adansonia digitata L. (baobab): a review of traditional information and taxonomic description. Asian Pacific Journal of Tropical Biomedicine. 2015; 5:79-84.

Sanchez AC, Osborne PE, Haq N. Identifying the global potential for baobab tree cultivation using ecological niche modelling. Agroforestry Systems. 2010; 80:191-201.

Sasaki H, Nishimura H, Chin M, Mitsuhashi H. Hyroxycinnamic acid esters of phenethylalcohol glycosides from Rehmannia glutinosa var. Purpurea. Phytochemistry. 1989; 28:875-879.

Sha' aban F, El-Naggar, Doskotch RW. Specioside: a new iridoid glycoside from Catalpa speciosa. Journal of Natural Products. 1980; 43:524-526.

Sticher VO, Afifi-Yazar FU. Minecoside und Verminoside, zwei neue iridoidglucoside aus Veronica officinalis L. (Scrophulariaceae). Helvetica Chimica Acta. 1979; 62:535-539.

Tundis R, Loizzo MR, Menichini F, Statti GA, Menichini F. Biological and pharmacological activities of iridoids: Recent developments. Mini-Reviews in Medical Chemistry. 2008; 8:399-420.

Xue Z, Yang B. Phenylethanoid glycosides: Research advance in their phytochemistry, pharmacological activity and pharmacokinetics. Molecules. 2016; 21:991-1015.

Young HS, Kim MS, Park HJ, Chung HY, Choi JS. Phytochemical study on Catalpa ovata. Archives of Pharmacal Research. 1992; 15:322-327.

Yusha'u M, Hamaza MM, Abdullahi N. Antibacterial activity of Adansonia digitata stem bark extracts on some clinical bacterial isolates. International Journal of Biomedical and Health Sciences. 2010; 6:129-135. 


\section{Highlights}

- $\quad$ This paper will present a systematic structural characterization of the constituents in baobab fruit pulp.

- All 13 compounds isolated were reported for the first time in the genus of Adansonia.

- $\quad$ An UHPLC HRAM MS method was used to conduct further investigation of the minor constituents of the hydro-alcohol baobab fruit pulp extract. 


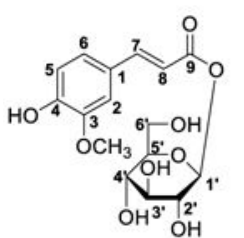

1

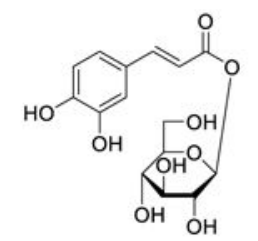<smiles>O=C(/C=C/c1ccc(O)c(O)c1)OCC1OC2OC(O)C(O)C1O2</smiles><smiles>O=C(/C=C/c1ccc(O)c(O)c1)OCC1OC2OC(O)C(O)C1O2</smiles>

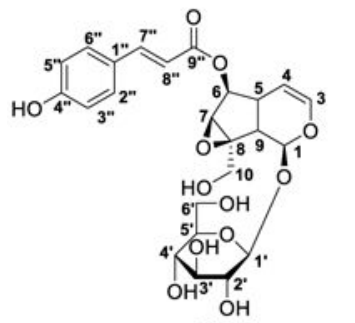

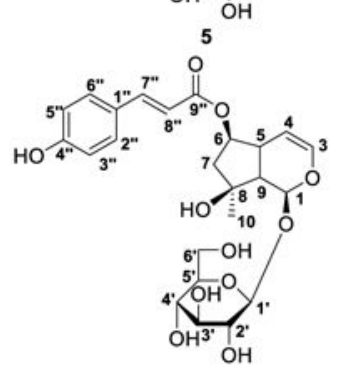

8
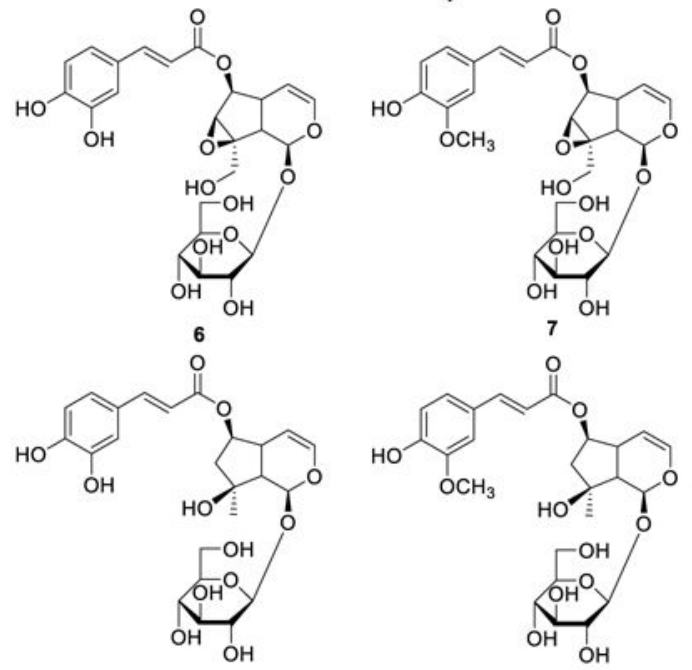

9

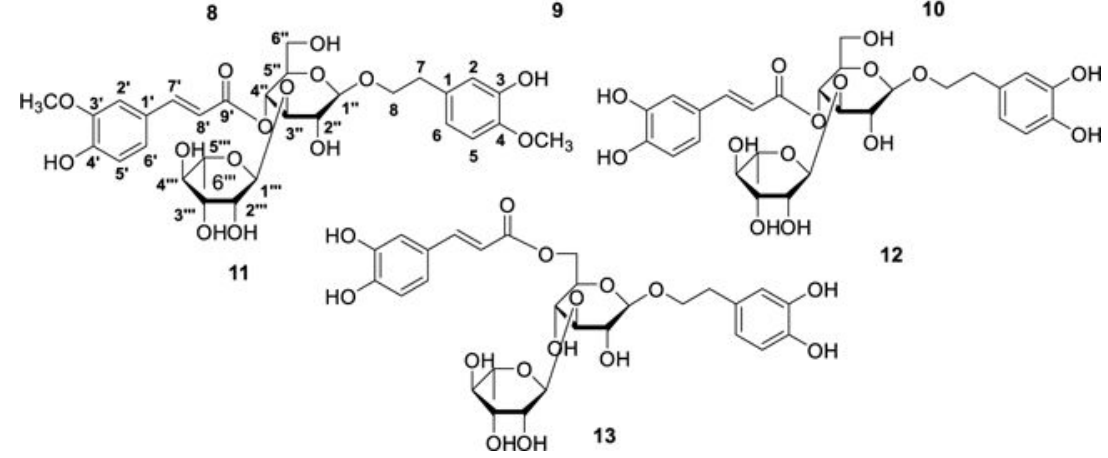

Figure 1.

Chemical structures of compounds 1-13. 


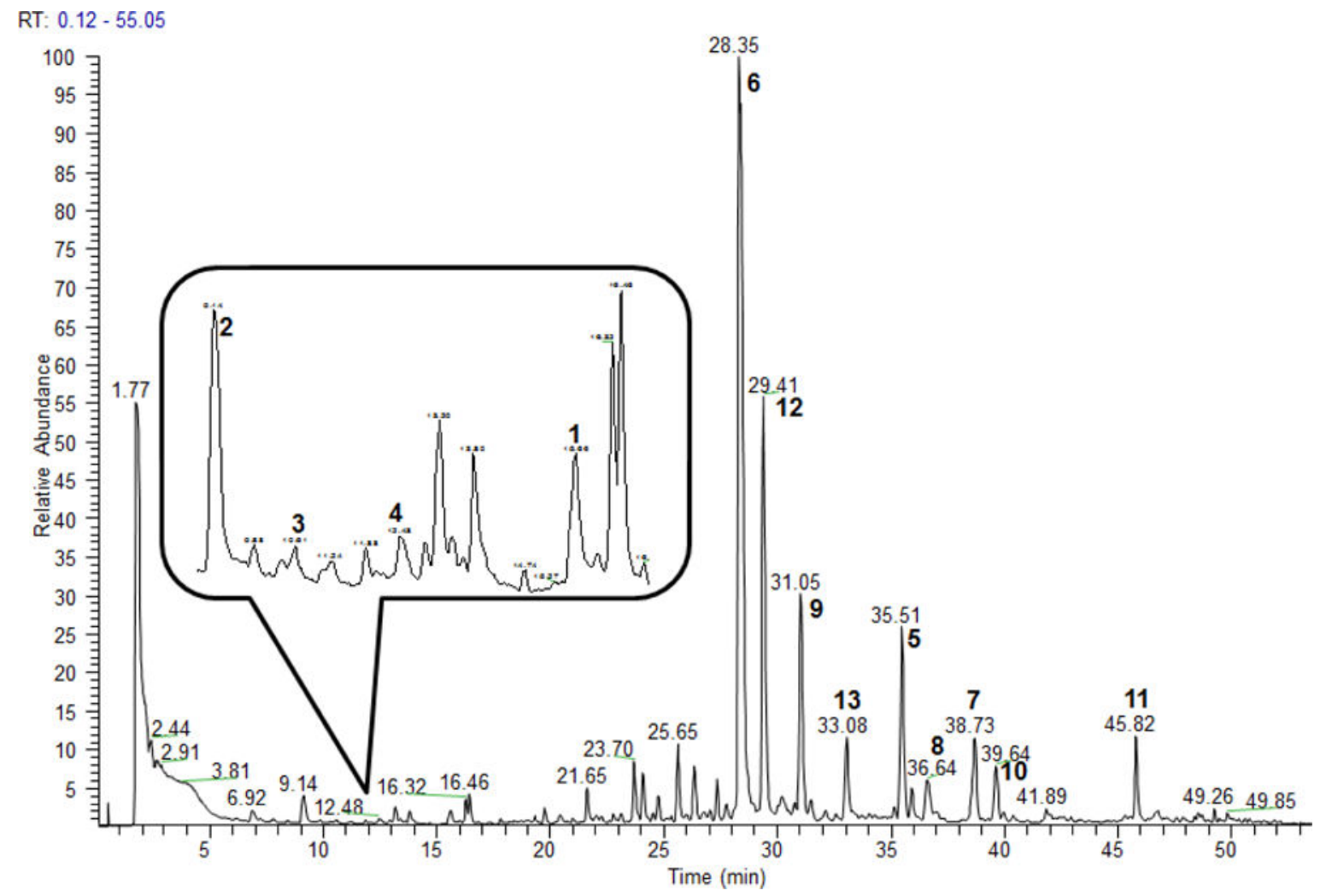

Figure 2.

Total ion chromatogram (TIC) of baobab 
RT: $0.00-58.70$

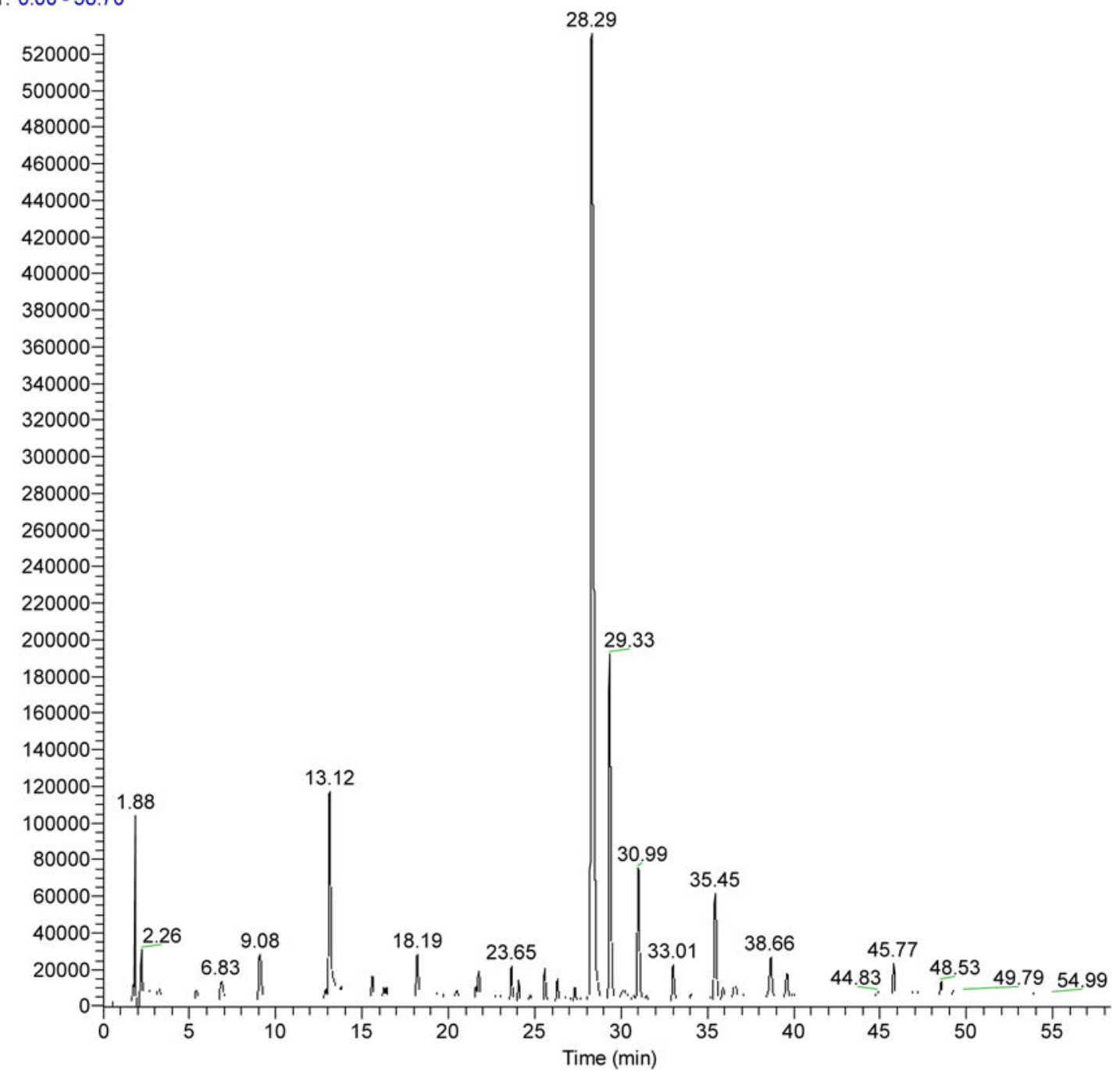

Figure 3.

PDA chromatogram of baobab 


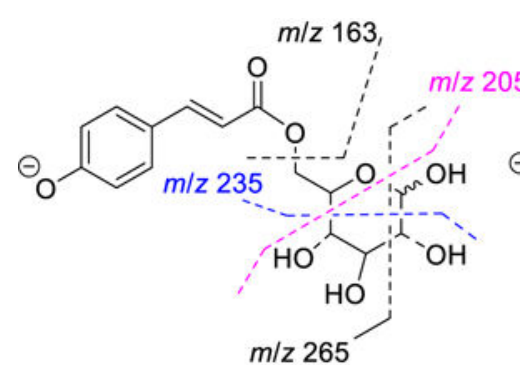

A

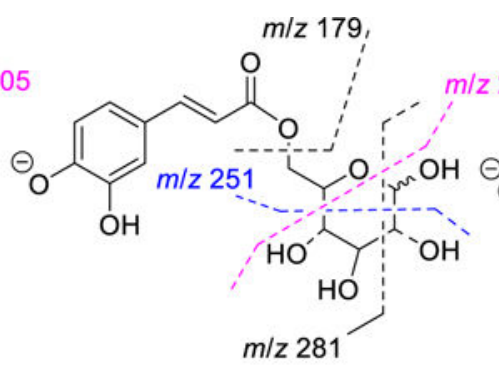

B

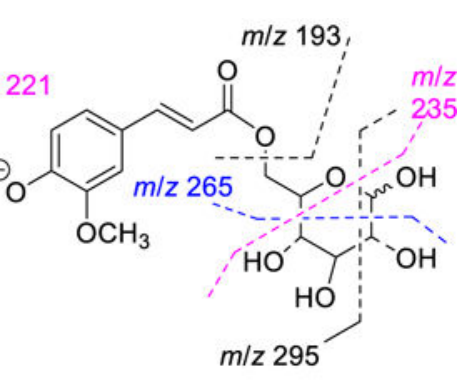

C

Scheme 1.

The proposed fragmentation pathways of 6- $O$ - $p$-coumaroylglucose (A), 6- $O$-caffeoylglucose (B) and 6-O-feruloylglucose (C). 
a:

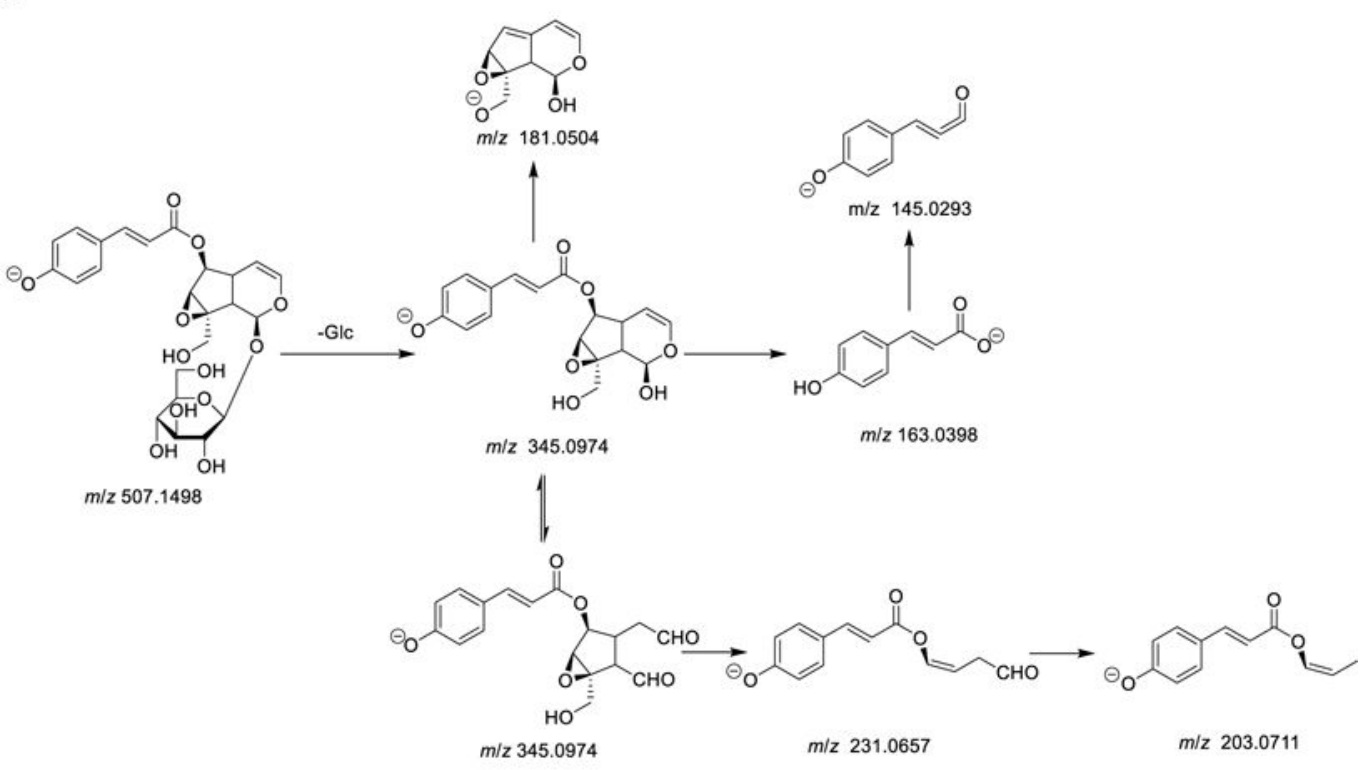

b:

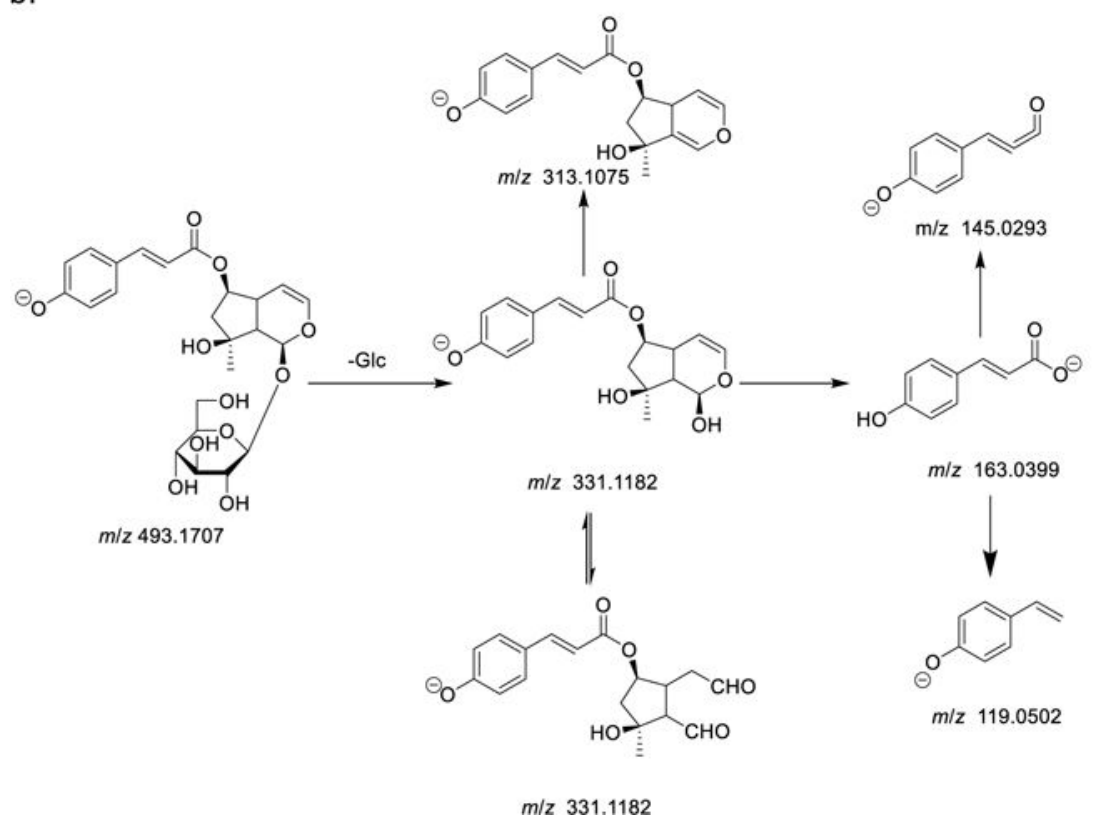

Scheme 2.

The proposed fragmentation pathways of two representative sub-classes of iridoid glycosides: (a) (-)-Specioside (5); (b) 6-O-p-coumaroylajugol (8). 


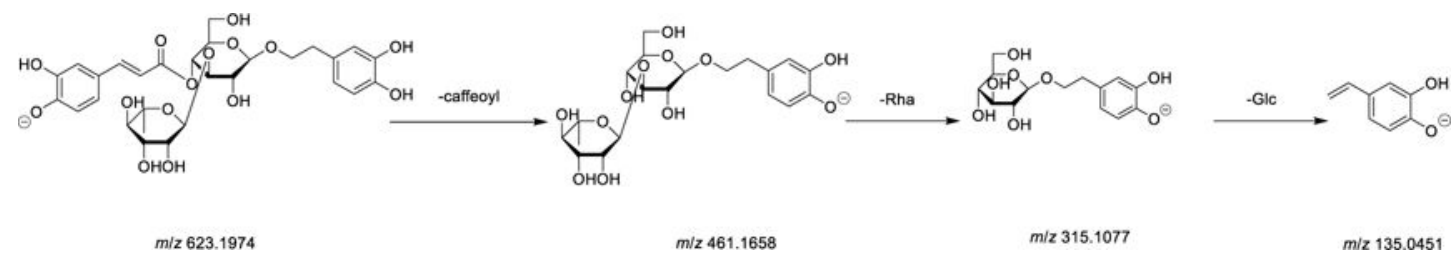

Scheme 3.

The proposed fragmentation pathways of acteoside (12). 


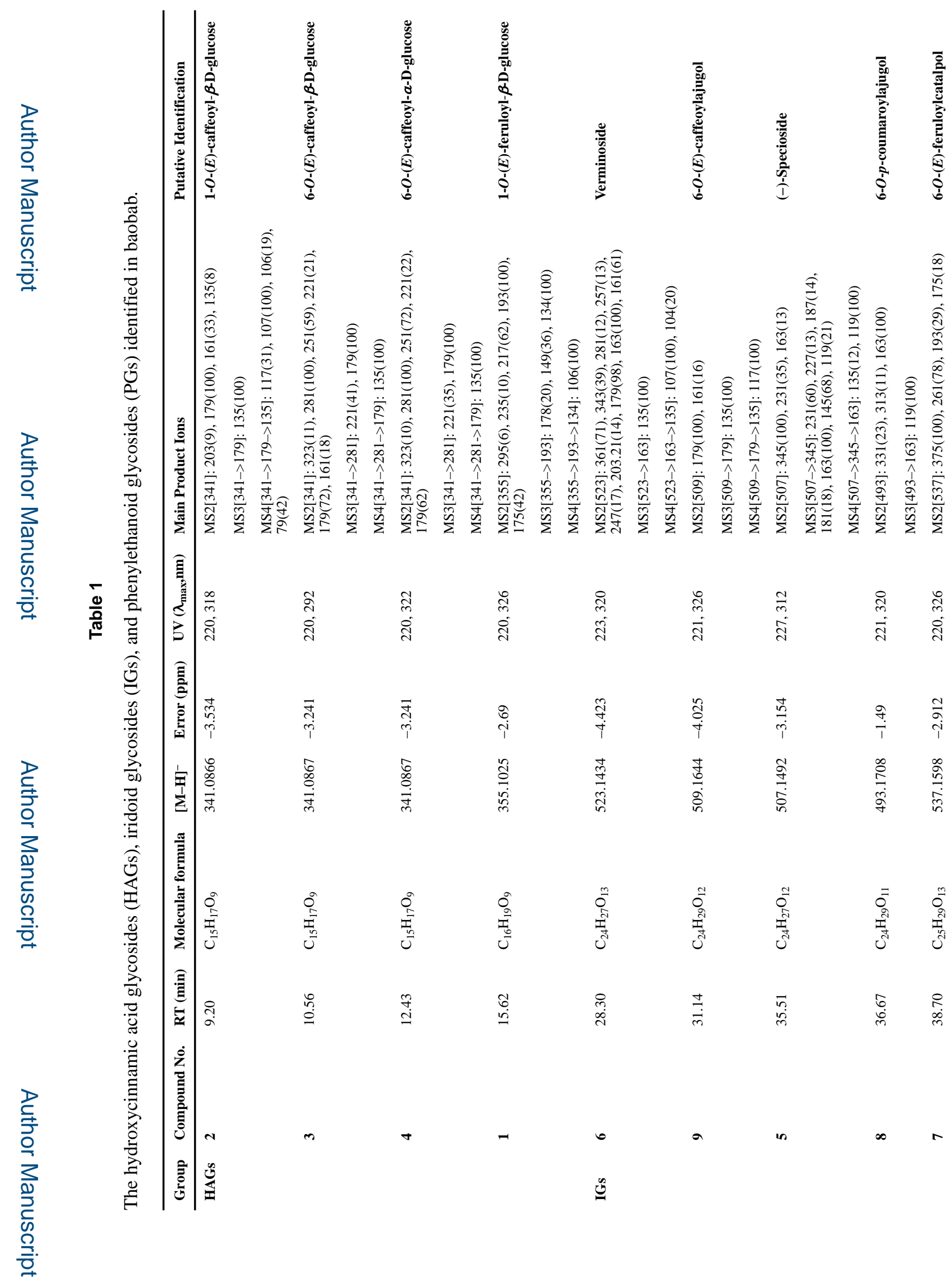

Food Res Int. Author manuscript; available in PMC 2018 September 01. 


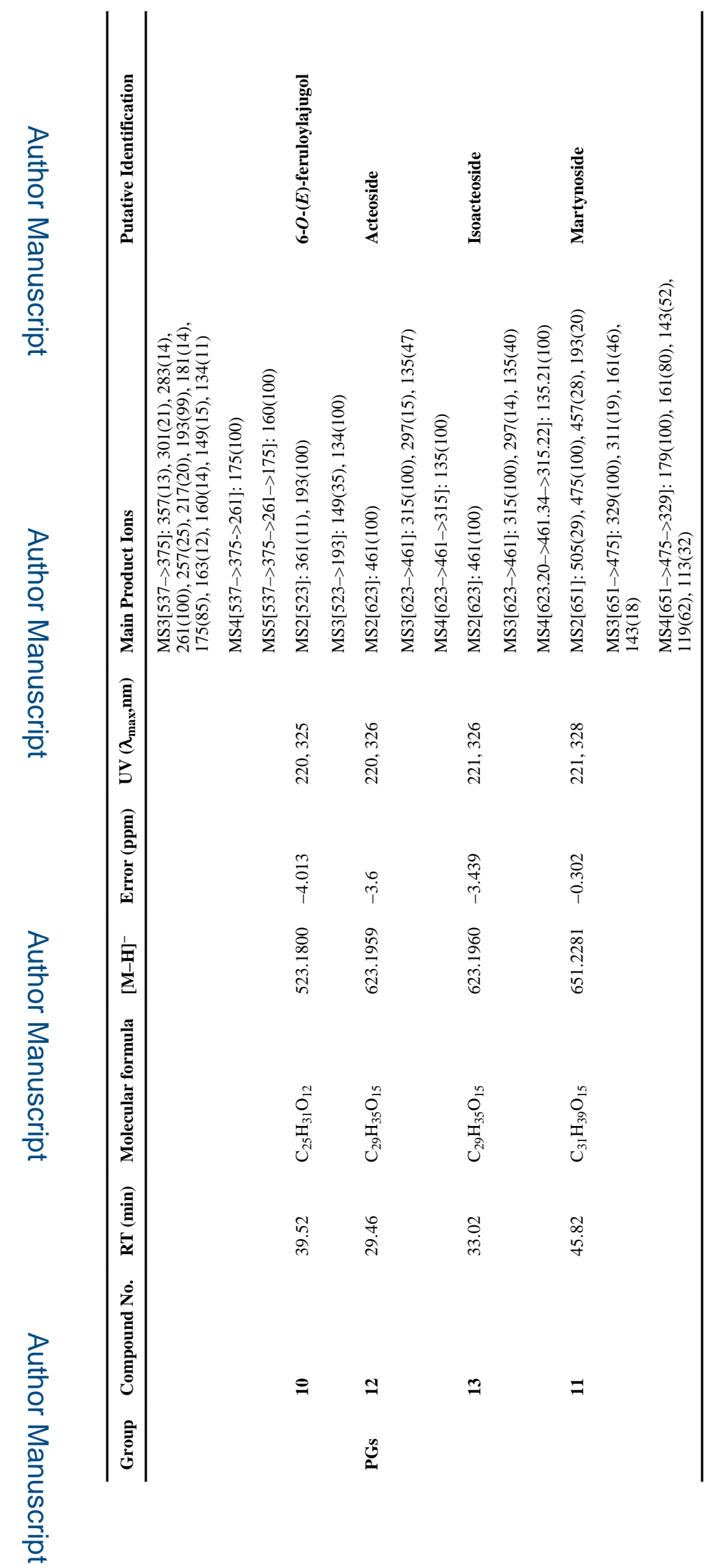

Food Res Int. Author manuscript; available in PMC 2018 September 01. 